$\mathrm{M}$ orality isn't just what your father, priest or favourite philosopher told you. It is a natural phenomenon, the result of a complex, evolved and learned set of capacities. Philosopher of neuroscience Patricia Churchland argues in Braintrust that human moral behaviour emerges from the mechanisms that evolved to promote social interactions.

Churchland hypothesizes that ethics is "a four-dimensional scheme for social behaviour that is shaped by interlocking brain processes". She identifies these dimensions as: caring, rooted in a biological attachment to kin and kith; the ability to recognize others' psychological states; problem-solving in a social context; and social learning. Different brain networks contribute to each. And even simple moral decisions, such as whether to steal another's possession, involve at least a few of these dimensions.

Churchland describes the biological mechanisms that serve these functions in an accessible way, and makes a case that they are fundamental to our moral practices. Although there is no clear argument that these dimensions are distinct, interlocking or sufficient to account for all aspects of ethical thought, she succeeds in painting a

"It is still open to us to question what values are the best to espouse."

picture of human

morality as emerging from the social interactions of intelligent animals primed for cooperative, context-sensitive behaviour.

The tour begins with the biology of "the most elemental" values: the neural hardware that grounds self-caring and well-being. Churchland's plausible claim is that our ability to value at all is rooted in the basic neural mechanisms that evolved to maintain human viability and reproductive success. These include neural pathways mediating negative and positive reinforcement learning, which underlie the experiences of pleasure, pain and fear; and hormones such as oxytocin and vasopressin, which figure in social interactions, pair bonding and care for offspring.

Thus, Churchland argues, human morality is formed on a neurobiological scaffold that evolved long ago, originally to promote care of self and offspring, and was later co-opted to foster more sophisticated cooperative interactions. She notes fascinating data that suggest that high-level social phenomena such as trust, generosity and punishment are influenced by levels of oxytocin and vasopressin.

Despite her naturalism, Churchland does not shy away from criticizing naturalistic views that she deems to be based on inadequate evidence. She argues that it is misleading to conceive of morality as innate, genetically specified or associated with one module in the brain. Although many social traits are genetically

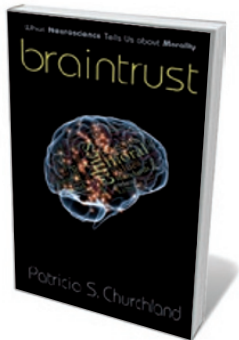

Braintrust: What Neuroscience Tells Us About Morality PATRICIAS CHURCHLAND Princeton Univ. Press: 2011. 288 pp. $\$ 24.95$ influenced, few can be linked to single genes. Instead, moral behaviour emerges as a solution to complex social problems.

She argues effectively against the popular view that humans share a "moral grammar" or a universal set of moral intuitions, but less convincingly against the position that human morality is built on a set of shared, emotion-involving sensitivities that become articulated differently in different cultures and environments. Churchland offers penetrating criticisms of arguments for the role of mirror neurons in theory of mind and empathy. These neurons respond when a monkey performs a certain goal-directed action, or sees that action being performed. Although mirror neurons are intriguing, they have been invoked to explain a wide variety of aspects of social neuroscience, often without adequate empirical or logical justification. Churchland's discussion puts these areas of research prone to over-interpretation into much-needed perspective.

Churchland demonstrates that there is substantial evidence that biology promotes social behaviour. But is all such behaviour necessarily good? Any behaviour, even free-riding, cheating and harming, must be supported by biology. How should we decide what is right? Many philosophers appeal to moral rules to address this question; Churchland sees no need, and criticizes those moral systems that take rules as foundational.

Churchland has Aristotelian sensibilities. The Aristotelian idea that morality depends $\rightarrow$ NATURE,COM

\section{More on the}

psychology of morals:

go.nature.com/alxpfa on the inculcation of good behavioural habits that promote human flourishing fits well with the author's evolutionary approach. She is less charitable to some other moral philosophers, such as Immanuel Kant, who grounded morality in the operation of reason. Although Churchland's argument that morality has biological roots demonstrates that our moral behaviour is not grounded in reason alone, her quick dismissal of a central role for deliberation in moral cognition potentially deprives us of valuable insights about the nature of human morality. For example, it may be the ability to step back from our biological inclinations and deliberate abstractly that defines human prosocial behaviour as uniquely moral.

So how do we ascertain which of the competing biological drives, urges and intuitions should govern our behaviour? This brings us to the descriptive-normative distinction, the famously unbridgeable gulf between "is" and "ought". Churchland tries to argue that this gulf is more apparent than real. But in my view, she goes too far in denying the legitimacy of this question. I am sympathetic to her position that knowing how things are (facts) can influence deliberation about what should be done (values). However, it is still open to us to question what values are the best to espouse, or whether human flourishing is the only good to which we ought to aim.

This perplexing question of moral authority seems obvious to people of faith. In the final chapter, Churchland faces head-on the challenge from religion. She does an excellent job of pointing out the inconsistencies and dangers in taking religious authority as grounds for moral authority. But where that leaves us remains unclear. Are we realists, relativists or nihilists? Churchland's biologycentred picture leaves open significant questions about the good and the right that will require philosophical, not biological, answers.

In my view, by illuminating the biological foundations on which caring, cooperation and social understanding are based, and by arguing against simplistic views about innateness and divine ordination, Churchland has delineated the conceptual space still to be navigated concerning which actions are morally right, how we come to those decisions, and how we justify them. Braintrust covers what science tells us about morality. But that is only one side of the story. -

Adina L. Roskies is an associate professor in the Department of Philosophy, Dartmouth College, New Hampshire 03755, USA. e-mail:adina.roskies@dartmouth.edu 